\title{
Compliance with Anti-Hypertensive Treatment and Associated Factors among Hypertensive Patients on Follow-Up in Jimma University Specialized Hospital, Jimma, South West Ethiopia: A Quantitative Cross- Sectional Study
}

\author{
Fiseha Girma ${ }^{1}$, Solomon Emishaw ${ }^{1}$, FessehayeAlemseged ${ }^{2}$ and Altayework Mekonnen ${ }^{3}$ \\ ${ }^{1}$ Department of Nursing, Mekelle University, Mekelle, Ethiopia \\ ${ }^{2}$ Department of Epidemiology, Jimma University, Jimma Ethiopia \\ ${ }^{3}$ Department of Nursing, Jimma University, Jimma, Ethiopia
}

\begin{abstract}
Objectives: Various explanations have been proffered to explain why a large percentage of patients have resistant hypertension, including secondary hypertension and endogenous resistance to treatment. However, the main reason for inadequate control of BP is poor compliance with the treatment regimen; both pharmacological and behavioral (e.g. weight reduction, sodium intake restriction, and exercise). Understanding the reasons for patient noncompliance with antihypertensive treatment is essential if BP is to be more effectively managed. The finding of this study will assist health care professionals to understand factors related to treatment compliance this enables them to manage hypertension appropriately both with medication and advising lifestyle interventions, also this study will be helpful to implement effective strategies that would lead to improved compliance, increased levels of controlled blood pressure and reduced occurrences of complications.
\end{abstract}

Background: Hypertension is defined as a systolic blood pressure greater than $140 \mathrm{mmHg}$ and a diastolic blood pressure greater than $90 \mathrm{mmHg}$ over a sustained period, based on the average of two or more blood pressure measurements taken in two or more contacts with the health care provider after an initial screening. Uncontrolled high blood pressure increases the risk of ischemic heart disease 3- to 4-fold, and the overall risk of cardiovascular disease 2- to 3-fold. Treatment of hypertension is multifaceted, requiring long-term compliance with both medication regimens and behavior modifications. Multiple factors contribute to the poor level of compliance with long-term antihypertensive therapy.The aim of this study is to assess the factors affecting compliance with antihypertensive treatment among hypertension patients on follow-up in Jimma University Specialized Hospital, South West Ethiopia.

Methods: This study was conducted at the Jimma University Specialized Hospital (JUSH) from February 2013 April 2013G.C. Simple random sampling techniques were employed to select 332 participants for this institution-based cross sectional study. A structured questionnaire was designed, translated, pre-tested, and utilized. Data were entered using Epidata3.1 and then exported to SPSS version 16 for analysis. Frequency distributions were used to organize the data and responses obtained. Multivariate logistic regression analysis was used to identify the factors, primarily affecting compliance with antihypertensive treatment.

Result: The mean age of participants was $53.8+12.8$ years. $55.7 \%$ of patients were compliant with antihypertensive medications and $24.8 \%$ were compliant in making lifestyle modifications. Factors significantly associated with treatment compliance included: age of the patient $(p=0.008)$, educational level $(O R=6.295 \% \mathrm{Cl} 1.8,20.9)$, number of antihypertensive drugs prescribed $(p=0.029)$, knowledge about hypertension treatment $(\mathrm{OR}=2.295 \% \mathrm{Cl} 1.1,4.3)$, patient perception about disease severity $(\mathrm{OR}=3.195 \% \mathrm{Cl} 1.6,5.8)$, and patient knowledge about the benefits of treatment compliance $(\mathrm{OR}=10.395 \% \mathrm{Cl} 3.8,27.8)$.

Conclusion: In this study, compliance with antihypertensive medication was only reported by $55.7 \%$ of patients, and compliance with lifestyle modifications was only reported by $24.8 \%$ of patients. The findings from this study can be used to pinpoint the factors that are contributing to poor treatment compliance among patients at the Jimma University Specialized Hospital and to educate them about proper management of hypertension.

\section{Keywords}

Hypertension; Patient compliance; Blood pressure

\section{Background}

Hypertension is defined as systolic blood pressure greater than 140 $\mathrm{mm} \mathrm{Hg}$ and a diastolic blood pressure greater than $90 \mathrm{~mm} \mathrm{Hg}$ over a sustained period, based on the average of two or more blood pressure measurements taken in two or more contacts with the health care provider after an initial screening [1].

About 1 in 8 deaths worldwide are due to hypertension and 4 million people die annually, thus making it the third largest killer in the world. The seriousness of hypertension as a global public health
*Corresponding author: Fiseha Girma, Department of Nursing Mekelle University, Mekelle, Ethiopia, Tel: 251 9078344; E-mail: fiseha1999@yahoo.com

Received August 01, 2014; Accepted September 02, 2014; Published September 05, 2014

Citation: Girma F, Emishaw S, Alemseged F, Mekonnen A.(2014) Compliance with Anti-Hypertensive Treatment and Associated Factors among Hypertensive Patients on Follow-Up in Jimma University Specialized Hospital, Jimma, South West Ethiopia: A Quantitative CrossSectional Study. J Hypertens 3: 174. doi:10.4172/2167-1095.1000174

Copyright: $\odot 2014$ Girma F, et al. This is an open-access article distributed under the terms of the Creative Commons Attribution License, which permits unrestricted use, distribution, and reproduction in any medium, provided the original author and source are credited. 
Citation: Girma F, Emishaw S, Alemseged F, Mekonnen A.(2014) Compliance with Anti-Hypertensive Treatment and Associated Factors among Hypertensive Patients on Follow-Up in Jimma University Specialized Hospital, Jimma, South West Ethiopia: A Quantitative CrossSectional Study. J Hypertens 3: 174. doi:10.4172/2167-1095.1000174

Page 2 of 6

problem is evident by its high prevalence and associated increase in cardiovascular complications in virtually all countries of the world [2]. In 2010, one of the three leading risk factors for global disease burden was arterial hypertension [3]. Hypertension contributes undeniably to both cardiovascular and cerebrovascular endpoints, including heart failure, myocardial infarction, and stroke [4]. Worldwide, $16.5 \%$ of all deaths can be attributed to high blood pressure. This includes $51 \%$ of deaths due to strokes and $45 \%$ of deaths due to coronary heart [3].

In sub-Saharan Africa, the prevalence of hypertension once thought to be low, has now assumed epidemic proportions. About 10 to 20 million people are affected with hypertension in the region. Effects of Westernization, urbanization, changes in dietary patterns and sedentary lifestyles are among the factors fuelling the epidemic of hypertension in sub-Saharan Africa [5].

The relationship between hypertension and heart disease is well established, and recent statements from American heart association and the JNC on detection, prevention, evaluation treatment of hypertension have emphasized the importance of maintaining low blood pressure for prevention of heart disease and stroke $[1,6]$.

Despite improvements in the detection and treatment of hypertension since the 1970 s, recent survey results illustrate that the condition continues to contribute, significantly, to mortality and morbidity in adults and that it is often poorly controlled in clinical practice [1]. Similarly, other studies suggest that the treatment's efficacy, in patients under care, is attenuated mainly by patient noncompliance with medication and lifestyle advice [7].

Multiple factors contribute to poor compliance with long-term antihypertensive therapy. Many patients have negative attitudes towards taking medication, especially if they 'feel well' [8]. Some factors reported to have a significant effect on compliance are: poor socioeconomic status (poverty), low level of education, unemployment, lack of effective social support networks, unsTable living conditions, long distance from treatment centers, high cost of transport, cultural and lay beliefs about illness and treatment, and forgetfulness [9]. A lack of knowledge about the severity of the disease and the importance of adhering to the prescribed treatment, and a lack of motivation to make some lifestyle changes in terms of diet and physical exercise may constitute barriers to compliance behavior [10].

Thus, such factors must be understood; however there is no study done particularly in the study area. Therefore, this study assessed compliance with anti hypertension treatment and associated factors among hypertensive patients on follow up in JUSH.

\section{Methods}

\section{Study area and period}

This study was conducted at the Jimma University Specialized Hospital (JUSH) from February 2013 - April 2013G.C. JUSH which is found in Jimma town; is the only teaching and referral hospital in the southwestern part of the country. It runs an annual governmental budget of 25.06 million Birr with a bed capacity of 450 and a total of more than 750 staffs of both supportive and professional. It provides services for approximately 9000 inpatient and 80,000 outpatient attendances a year. The hospital gives both inpatient and outpatient services. As one of the outpatient services, the hospital has specialty clinics where patients with specific chronic disease are referred for follow-up. Hypertension clinic is one of those clinics which give service for patients with hypertension disorder. The clinic currently gives service for about 2237 hypertension patients.

\section{Study design}

This study used institution based Cross sectional quantitative study design.

\section{Study participants}

The study population was hypertensive patients on follow up in the hypertension clinic of JUSH who were placed in treatment for more than three months and those who were above 18 years of age.

\section{Sampling procedure}

The sample size was determined by using sample size determination for estimation of a single population proportion formula. The following assumptions were considered; estimate of $\%$ of hypertensive patient who are compliant with antihypertension treatment was taken $65 \%$ [11]. The margin of sampling error tolerated 5\% (0.05), and 95\% confidence level. After applying finite population correction and adding $10 \%$ non response rate the final sample size became 332 . The patient's card number was used as a sampling frame and individual patients was selected by using simple random sampling from a total of 2237 patients on follow up in chronic illness clinic.

\section{Data collection}

The data were collected from hypertensive patients using pre tested structured questionnaires and by reviewing patient chart. Questions were developed for this study to assess social demography, clinical characteristics, knowledge about hypertension treatment, compliance with lifestyle instructions, perceptions of the patients, locus of control, and service related factors.

Compliance to medication regimen was assessed by using the revised morisky 8 item medication adherence scale which has a high reliability (Alpha Reliability $=0.83$ ) [12]. The data were collected by 5 trained nurses working in JUSH other than chronic illness department who can speak both Amharic and Affan Oromo through face to face interview and record review. Patients were interviewed after they get the service they required from hypertension clinic using pretested questionnaire. Also patient chart was reviewed by using structured check list. The items were formulated in a manner that elicits the required data from the chart.

\section{Data analysis}

Data were entered by using Epidata3.1 and then exported to SPSS version 16 for analysis. Frequency distributions were used to organize the data and present the responses obtained. Measures of central tendency were calculated and utilized for appropriate variables to describe the data. Bivariate and multivariate logistic regression were done using Compliant vs. non-compliant status as the outcome variable, while various study variables were used as independent variables. A p-value of less than 0.05 was considered to be statistically significant in multivariate analysis.

\section{Data quality management}

A questionnaire was prepared in English and translated to Amharic \& Affan Oromo and retranslated back into English. One day training was given for five Bsc nurse data collectors ahead of the actual data collection period. The training was focused on familiarizing interviewers with the questionnaire and giving them the opportunity to practice using it. The training also includes holding a discussion about different sections of the questionnaire, using a question by question description. Data collectors practiced interviewing to identify any possible future problems and to take remedial measures. 
Citation: Girma F, Emishaw S, Alemseged F, Mekonnen A.(2014) Compliance with Anti-Hypertensive Treatment and Associated Factors among Hypertensive Patients on Follow-Up in Jimma University Specialized Hospital, Jimma, South West Ethiopia: A Quantitative CrossSectional Study. J Hypertens 3: 174. doi:10.4172/2167-1095.1000174

A questionnaire was pre-tested on $5 \%$ of the sample a week before the actual data collection period in Limmu hospital; after pre-test necessary modification was done. At the time of data collection, filled questionnaires were checked for completeness and consistency of information by the supervisor on a daily basis and typographic errors were manually edited. Any ambiguity and other problems of data collectors were addressed by communicating with the data collectors before the following week.

\section{Ethical considerations}

The ethical clearance letter was obtained from an ethical review committee of the JU College of public health and medical sciences. The respondents were informed about the purpose of the study, and their oral consent was obtained before the data collection. The respondents' right to refuse or withdraw from participating in the interview was fully maintained and the information provided by each respondent kept strictly confidential.

\section{Operational definitions}

Knowledge: One point was given for the correct answers and zero for the incorrect answers. The knowledge scores were divided into two levels which are good knowledge and poor knowledge using the mean knowledge score as the cutoff point.

Compliance: with the medication regimen: Respondents who score $80 \%$ and above on the revised Morisky 8-Item Medication Adherence Scale were considered as compliant and respondents with a score $<80 \%$ were considered as non compliant [13].

Perception: of the severity of hypertension: Respondents with an average score of 3 and above were regarded as having a high perception of severity of hypertension and those with an average score of below 3 as having a low perception of severity of hypertension.

Perception: of the benefits of compliance to hypertension treatment: Respondents with an average score of 3 and above were regarded as having a positive perception of benefits and those with scores of below 3 as negative perception of benefits.

Khat: The fresh leaves and twigs of a shrub that have a stimulating and euphoric effect when chewed or brewed as tea.

\section{Result}

\section{Socio demographic characteristics}

Out of 332 hypertensive patient planned to be included in the study, 314 were interviewed, 12 were not present during the data collection period, 4 refused to participate and 2 were too sick to be interviewed, which gives a response rate of $94.5 \%$.Among the study participants, 161 (51.3\%) and 153 (48.7\%) were females and males respectively. The mean age of the participant was 53.8 years with a standard deviation of 12.8 years. The majority of participants, namely $214(68.2 \%)$ were married, 10 (3.2\%) were single, 64 (20.4\%) were widowed and $26(8.3 \%)$ were divorced (Table 1 ).

\section{Clinical characteristics}

Evidence of Co morbidity, like DM, heart failure or renal disease was not noted among the $213(67.8 \%)$ of the study participants, but 92 (29.3\%) had one and 9 (2.9\%) had two or more Co morbidities. This study showed that blood pressure was controlled in $174(55.4 \%)$ and uncontrolled in 140 (44.6\%) of patients. Regarding medication, nearly half $(47.5 \%)$ of the participants took 2 drugs and those participants who took their medication once daily were 167 (53.2\%) (Table2).

\section{Knowledge and perceptions of the study participants}

Regarding participant's knowledge about hypertension treatment only $138(43.9 \%)$ was knowledgeable. Two hundred fifty (79.6\%) study participants were found to have a high perception of the benefits of compliance to anti-hypertensive treatment. The majority of participants, namely 251 (79.9\%) had higher perceptions of susceptibility to hypertension related complications while $63(20.1 \%)$ had low perceptions. In this study, more than half $(61.8 \%)$ of the participants perceived their disease as severe. Also, this study showed that $63.7 \%$ of the participants had a good perception of service related factors (Table 3).

\section{Compliance to antihypertension medication}

According to $80 \%$ cutoff level using MMAS, 175 (55.5\%) of the study participants complied with antihypertension medication regimen while the rest 139 (44.3\%) were non compliant with antihypertensive medication regimen. Of the total 314 study participants $66(21 \%)$ skipped taking medication once or more in the past three days, of them 34 (51.5\%), 17 (25.8\%), 9 (13.6\%) and 5 (7.6\%) mentioned forgetting to take medication, feeling better, unable to buy, and due to side effects respectively for the reason to skip doses.

\section{Compliance with lifestyle interventions}

Out of 314 hypertensive patients participated in the study only $4.5 \%$ of them were smokers, $172(54.8 \%)$ were not having salt restriction, $59.2 \%$ adapted DASH plan, $63.7 \%$ maintained their normal weight and $36.3 \%$ use to do regular physical exercise. Two hundred eighty (89.2\%) participants were compliant with instructions about alcohol consumption. In this study, the overall compliance to lifestyle instructions was noted only on one fourth $(24.8 \%)$ of the participants, the others $236(75.2 \%)$ are non compliant with lifestyle instructions.

\section{Factors associated with compliance with anti hypertensive medications}

All variables were considered in the bivariate analysis and those variables with a $p$ value $<0.2$ in bivariate analysis were included in the multivariate analysis. The association between compliance to antihypertension medication and certain explanatory variables was further investigated using multivariate logistic regression. Those variables with $\mathrm{P}$-value $<0.05$ were considered as predictors of compliance to anti hypertension medication.

Multivariate logistic regression revealed that compliance was more likely among patients in the age group between 41 to 60 years $(\mathrm{OR}=3.4$ $95 \%$ CI 1.5, 7.6) and above 60 years (OR=2.8 95\% CI 1.6, 6.9) than those who are between age 18 to 40 years. Participants who completed their education from grade $9-12$ were more than 6 (OR=6. 2 95\% CI 1.8, 20.9) times compliant with anti hypertensive medication compared to those who were illiterate. The odds of compliance to antihypertension medication was higher among hypertensive patients who took only one, two and three drugs in relation to those who took four and above drugs (OR=10.1 95\% CI 1.9, 51.7) $(\mathrm{OR}=8.495 \%$ CI 1.9, 38.3) $(\mathrm{OR}=10$. 9 95\% CI 2.2,53.4) respectively. Compliance to anti hypertensive medication was also higher (OR=2.2 95\% CI 1.1, 4.3) among study participants who were knowledgeable about hypertension treatment compared to those who had less knowledge about the treatment. In this study patient perception about the disease severity and benefits of compliance to the treatment had a positive association with compliance with antihypertensive medication. The odds of compliance to antihypertension medication was higher among hypertensive patients 
Citation: Girma F, Emishaw S, Alemseged F, Mekonnen A.(2014) Compliance with Anti-Hypertensive Treatment and Associated Factors among Hypertensive Patients on Follow-Up in Jimma University Specialized Hospital, Jimma, South West Ethiopia: A Quantitative CrossSectional Study. J Hypertens 3: 174. doi:10.4172/2167-1095.1000174

\begin{tabular}{|c|c|c|c|}
\hline Variables & Category & Frequency & percentage \\
\hline \multirow{3}{*}{ Age in years } & $18-40$ & 62 & 19.7 \\
\hline & $41-60$ & 168 & 53.5 \\
\hline & $>=60$ & 84 & 26.8 \\
\hline \multirow{5}{*}{ Ethnicity } & Oromo & 158 & 50.3 \\
\hline & Amhara & 78 & 24.8 \\
\hline & Dawero & 30 & 9.6 \\
\hline & Yeme & 25 & 8 \\
\hline & Other & 23 & 7.3 \\
\hline \multirow{4}{*}{ Religion } & Orthodox & 128 & 40.8 \\
\hline & Muslim & 151 & 48.1 \\
\hline & Protestant & 33 & 10.5 \\
\hline & Others $^{1}$ & 2 & 0.6 \\
\hline \multirow{7}{*}{ Occupation } & Gov't employed & 46 & 14.6 \\
\hline & Merchant & 27 & 8.6 \\
\hline & Farmer & 109 & 34.7 \\
\hline & Housewife & 64 & 20.4 \\
\hline & Day laborer & 17 & 5.4 \\
\hline & Have no work & 33 & 10.5 \\
\hline & Others $^{2}$ & 18 & 5.7 \\
\hline \multirow{4}{*}{ Educational status } & Illiterate & 150 & 47.8 \\
\hline & Grade 1- 8 & 103 & 32.8 \\
\hline & Grade 9- 12 & 32 & 10.2 \\
\hline & 12 and above & 29 & 9.2 \\
\hline \multirow{3}{*}{ Family income } & $<500$ birr & 155 & 49.4 \\
\hline & $500-1000$ birr & 94 & 29.9 \\
\hline & $>1000$ birr & 65 & 20.7 \\
\hline \multirow{2}{*}{$\begin{array}{c}\text { Time to reach the } \\
\text { hospital (single trip) }\end{array}$} & Up to one hour & 174 & 55.4 \\
\hline & Greater than one hour & 140 & 44.6 \\
\hline \multirow{4}{*}{ Cost covered } & Self & 173 & 55.1 \\
\hline & Family & 67 & 21.3 \\
\hline & Free & 72 & 22.9 \\
\hline & Employer organization & 2 & 0.6 \\
\hline
\end{tabular}

$[8,11,16]$. The difference can be because of the large variation in the knowledge level of the study group and the inability of the study participants to afford for a medication fee since most $(55.1 \%)$ of the study participants were expected to pay for their medication expenses.

Inadequate compliance with antihypertensive medications likely contributes to a failure to contribute to attain BP goal, as poor compliance is associated with sub optimal clinical outcomes [17]. A study done in Australia shows that elderly patients with no prior history of CVD who adhere with their antihypertensive medication regimen were less likely to experience CV morbidity and death than those who were non adherent [18].

Age was found to be significantly and independently associated with compliance with antihypertension medication in this study, with better adherence observed in older people. This finding is consistent with a number of other studies $[8,19]$. Poor compliance in younger patients may be due to ignorance of the true nature of hypertension, denial of the existence of the disease or becoming busy with activities outside the home that makes them forget taking medications.

Education may lead to better understanding of the risks involved in non-compliant behavior. Literate persons and those who are motivated to know more about their illness are more susceptible to health education than illiterate persons. Patients who completed grade

\begin{tabular}{|c|c|c|c|}
\hline Variables & Category & Frequency & percentage \\
\hline \multirow{5}{*}{ Duration on treatment } & 1 year or less & 79 & 25.2 \\
\hline & 1 - 3years & 134 & 42.7 \\
\hline & $3-5$ years & 57 & 18.2 \\
\hline & $5-7$ years & 27 & 8.6 \\
\hline & $>7$ years & 17 & 5.4 \\
\hline \multirow{3}{*}{ Presence of health compliant } & None & 189 & 60.2 \\
\hline & One & 79 & 25.2 \\
\hline & Two and above & 46 & 14.6 \\
\hline \multirow{4}{*}{ Number of drugs } & One & 51 & 16.2 \\
\hline & Two & 149 & 47.5 \\
\hline & Three & 97 & 30.9 \\
\hline & Four and above & 17 & 5.4 \\
\hline \multirow{3}{*}{ Dosage } & Once & 167 & 53.2 \\
\hline & BID & 142 & 45.2 \\
\hline & TID and above & 5 & 1.6 \\
\hline \multirow{2}{*}{ Type of hypertension } & Primary & 297 & 94.6 \\
\hline & Secondary & 17 & 5.4 \\
\hline \multirow{2}{*}{$\begin{array}{l}\text { History of hospital } \\
\text { admission }(n=314)\end{array}$} & Yes & 90 & 28.7 \\
\hline & No & 224 & 71.3 \\
\hline \multirow{2}{*}{$\begin{array}{l}\text { Hypertension related } \\
\text { complication }\end{array}$} & Yes & 116 & 36.9 \\
\hline & No & 198 & 63.1 \\
\hline
\end{tabular}

Table 2: Clinical characteristics of hypertension patients on follow up $(\mathrm{n}=$ 314), JUSH, 2013. 
Citation: Girma F, Emishaw S, Alemseged F, Mekonnen A.(2014) Compliance with Anti-Hypertensive Treatment and Associated Factors among Hypertensive Patients on Follow-Up in Jimma University Specialized Hospital, Jimma, South West Ethiopia: A Quantitative CrossSectional Study. J Hypertens 3: 174. doi:10.4172/2167-1095.1000174

Page 5 of 6

\begin{tabular}{|c|c|c|c|}
\hline Variables & Category & Frequency & $\%$ \\
\hline \multirow{2}{*}{ Knowledge status $(n=314)$} & Knowledgeable & 138 & 43.9 \\
\hline & Less knowledgeable & 176 & 56.1 \\
\hline \multirow{2}{*}{ Perceived severity of hypertension $(n=314)$} & High & 194 & 61.8 \\
\hline & Low & 120 & 38.2 \\
\hline \multirow{2}{*}{ Perceived susceptibility to hypertension complication $(n=314)$} & High & 251 & 79.9 \\
\hline & Low & 63 & 20.1 \\
\hline \multirow{2}{*}{ Perceived benefits of compliance to hypertension treatment $(n=314)$} & High & 250 & 79.6 \\
\hline & Low & 64 & 20.4 \\
\hline \multirow{2}{*}{ Perceived barriers for compliance to hypertension treatment $(n=314)$} & High & 54 & 17.2 \\
\hline & Low & 260 & 82.8 \\
\hline \multirow{2}{*}{ Perception on Service related factors $(n=314)$} & Good & 200 & 63.7 \\
\hline & Poor & 114 & 36.3 \\
\hline \multirow{2}{*}{ Internal locus of control $(n=314)$} & High & 237 & 75.5 \\
\hline & Low & 77 & 24.5 \\
\hline
\end{tabular}

Table 3: Distribution of hypertension patients on follow up based on knowledge and perceptions ( $\mathrm{n}=314), \mathrm{JUSH}, 2013$

\begin{tabular}{|c|c|c|c|c|}
\hline Variables & Category & $\begin{array}{l}\text { Compliant to antihypertension } \\
\text { medications }\end{array}$ & COR $(95 \% \mathrm{Cl})$ & AOR $(95 \% \mathrm{Cl})$ \\
\hline \multirow{3}{*}{ Age } & $18-40$ & $29(46.8)$ & 1 & 1 \\
\hline & $41-60$ & $101(60.1)$ & $1.7(0.9,3.1)$ & $3.4(1.5,7.6)^{\star \star}$ \\
\hline & $>=60$ & $45(53.6)$ & $1.3(0.7,2.5)$ & $2.8(1.6,6.9)^{\star \star}$ \\
\hline \multirow{4}{*}{ Educational level } & Illiterate & $70(46.7)$ & 1 & 1 \\
\hline & Grade 1- 8 & $65(63.1)$ & $1.9(1.2,3.3)^{*}$ & $1.4(0.7,2.8)$ \\
\hline & Grade 9- 12 & $26(81.2)$ & $4.9(1.9,12.7)^{\star}$ & $6.2(1.8,20.9)^{\star *}$ \\
\hline & 12 and above & $14(48.3)$ & $1.1(0.5,2.4)$ & $0.6(0.2,1.7)$ \\
\hline \multirow{4}{*}{ Number of drug } & One & $31(60.8)$ & $7.2(1.8,28.4)^{\star}$ & $10.1(1.9,51.7)^{\star *}$ \\
\hline & Two & $81(54.4)$ & $5.6(1.5,20.2)^{\star}$ & $8.4(1.9,38.3)^{\star *}$ \\
\hline & Three & $60(61.9)$ & $7.6(2.0,28.1)^{\star}$ & $10.9(2.2,53.4)^{\star *}$ \\
\hline & Four and above & $3(17.6)$ & 1 & 1 \\
\hline \multirow{2}{*}{ Knowledge status } & Knowledgeable & $96(69.6)$ & $2.8(1.8,4.5)^{\star}$ & $2.2(1.1,4.3)^{* *}$ \\
\hline & Less knowledgeable & $79(44.9)$ & 1 & 1 \\
\hline \multirow{2}{*}{ Perceived severity } & High & $144(74.2)$ & $8.3(4.9,13.9)^{*}$ & $3.1(1.6,5.8)^{\star *}$ \\
\hline & Low & $31(25.8)$ & 1 & 1 \\
\hline \multirow{2}{*}{ Perceived benefits } & High & $167(66.8)$ & $14.1(6.4,30.9)^{\star}$ & $10.3(3.8,27.8)^{\star *}$ \\
\hline & Low & $8(12.5)$ & 1 & 1 \\
\hline
\end{tabular}

Note * Significant in bivariate analysis ** in multivariate analysis

Table 4: Multivariate logistic regression model showing predictors of compliance to antihypertension medication, JUSH, 2013 G.C

9 -12 were found to become more compliant with antihypertension medications than those who are illiterate. The finding is in line with research done in Nigeria [20] but the finding of this study is inconsistent with many studies showing no significant associations between the variables $[11,19,21,22]$.

The complexity of the regimen is one of treatment-related factors that have been identified as a possible cause of noncompliance. Number of drugs was found to have strong associated with compliance to antihypertension medication. Patients who took three or less drugs daily were more likely to be compliant than those who took four or more drugs daily. This is in contrast with study in Pakistan [8] and Nigeria [20] that demonstrates patients who took multiple drugs were more likely to be compliant. The good compliance in patients who took fewer drugs may perhaps be that when patients have to take fewer drugs, they may not feel the pill burden and gets compliance easy.

Good knowledge about hypertension and its management is an essential part of successful treatment. The finding of this study revealed that there is a positive association between knowledge about 
Citation: Girma F, Emishaw S, Alemseged F, Mekonnen A.(2014) Compliance with Anti-Hypertensive Treatment and Associated Factors among Hypertensive Patients on Follow-Up in Jimma University Specialized Hospital, Jimma, South West Ethiopia: A Quantitative CrossSectional Study. J Hypertens 3: 174. doi:10.4172/2167-1095.1000174

hypertension treatment and compliance with anti hypertensive medications. The finding is in line with other studies done in Gondar, Ethiopia and Pakistan $[8,11]$

The finding of this study is concordant with the health belief model [23] showing perceived severity and perceived benefits to have a positive association with compliance to antihypertension medication. In this study, patients who highly perceive hypertension as Savior and those who have high perceptions of the benefits of compliance to hypertension treatment were more likely to be compliant with antihypertension medication. Also the strong positive association between perceived benefit and compliance to antihypertension medication is in line with other study done in Seychelles [19] and also supported by a study in England that revealed compliant respondents reported the perceived benefits they derived from taking medication as one of the reasons for their compliance [24].

\section{Strength of the study}

This study used reviewing patient charts and self reporting as a method of data collection which increased the reliability of the result. The use of validated tool (MMAS) in this study further strengthens the reliability of our results.

\section{Limitations}

Since it is difficult to assess the characteristics of non responders, this study assumed that responders and non-responders are similar in distribution of the recorded variables. Cause and effect cannot be ascertained since it was a cross sectional study.

\section{Conclusions}

It is concluded that the compliance with hypertension treatment, both for anti hypertension medications and lifestyle modification is still suboptimal among hypertension patient to follow up. Compliance to antihypertension medication is only reported by $55.7 \%$ of patients and compliance to lifestyle instructions was found to be only $24.8 \%$ among the patients in the study area. In the study area patients know little about hypertension and its management. Even though more than half of patients maintained their blood pressure normal, it is not at a satisfactory level.

\section{Authors' contribution}

FG wrote the proposal, participated in data collection, analyzed the data and drafted the paper. FA and AM participated by revising and approving the proposal, data analysis and revised subsequent drafts of the paper. SE has been involved in drafting the manuscript. All authors read and approved the final manuscript.

\section{Authors' information}

FG is lecturer of Medical surgical nursing in the department of nursing of Mekelle University,the FA is associate professor of epidemiology in college of public health and medical science of Jimma University, AM is senior lecturer in the Jimma university department of nursing and teaches in the postgraduate program. SE is lecturer of emergency medicine and critical care nursing in the nursing department of Mekelle University. All authors are currently staff members in their respective departments in Jimma University and Mekelle University.

\section{Acknowledgment}

We would like to thank Jimma University for providing funding to conduct the study. We would also like to forward our gratitude to all data collectors, facilitato and study participants involved in this study.Also, we would like to thank Hannah Yang (BS, MSPH in Global disease epidemiology) who copyedited the manuscript.

\section{References}

1. Chobanian AV, Bakris GL, Black HR, Cushman WC, Green LA, et al. (2003) The Seventh Report of the Joint National Committee on Prevention, Detection,
Evaluation, and Treatment of High Blood Pressure: the JNC 7 report. JAMA 289: 2560-2572.

2. Khatib O (2004) Noncommunicable diseases: risk factors and regional strategies for prevention and care. East Mediterr Health J 10: 778-788.

3. Lim SS, Vos T, Flaxman AD, Danaei G, Shibuya K, et al. (2012) A comparative risk assessment of burden of disease and injury attribuTable to 67 risk factors and risk factor clusters in 21 regions, 1990-2010: a systematic analysis for the Global Burden of Disease Study 2010. Lancet 380: 2224-2260.

4. Go AS, Mozaffarian D, Roger VL, Benjamin EJ, Berry JD, et al. (2013) Hear disease and stroke statistics--2013 update: a report from the American Heart Association. Circulation 127: e6-6e245.

5. Opie LH, Seedat YK (2005) Hypertension in sub-Saharan African populations Circulation 112: 3562-3568.

6. Greenland P, Knoll MD, Stamler J, Neaton JD, Dyer AR, et al. (2003) Major risk factors as antecedents of fatal and nonfatal coronary heart disease events. JAMA 290: 891-897.

7. Lüscher TF, Vetter $H$, Siegenthaler W, Vetter W (1985) Compliance in hypertension: facts and concepts. J Hypertens Suppl 3: S3-9.

8. Hashmi SK, Afridi MB, Abbas K, Sajwani RA, Saleheen D, et al. (2007) Factors associated with adherence to anti-hypertensive treatment in Pakistan. PLoS One 2: e280.

9. Akpa MR, Agomuoh DI, Odia OJ (2005) Drug compliance among hypertensive patients in Port Harcourt, Nigeria. Niger J Med 14: 55-57.

10. Campbell NR, Petrella R, Kaczorowski J (2006) Public education on hypertension: a new initiative to improve the prevention, treatment and control of hypertension in Canada. Can J Cardiol 22: 599-603.

11. Abere D Ambaw, Getahun A Alemie, Solomon M W/Yohannes,et al. (2012) Adherence to antihypertensive treatment and associated factors among patients on follow up at University of Gondar Hospital, Northwest, Ethiopia. BMC Public Health. 12: 282.

12. Morisky DE, Ang A, Krousel-Wood M, Ward HJ (2008) Predictive validity of a medication adherence measure in an outpatient setting. $\mathrm{J}$ Clin Hypertens (Greenwich) 10: 348-354.

13. Barber N (2002) Should we consider non-compliance a medical error? Qual Saf Health Care 11: 81-84.

14. Almas A, Hameed A, Ahmed B, Islam M (2006) Compliance to antihypertensive therapy. J Coll Physicians Surg Pak 16: 23-26.

15. Osamor PE, Owumi BE (2011) Factors associated with treatment compliance in hypertension in southwest Nigeria. J Health Popul Nutr 29: 619-628.

16. Habtamu A, Mesfin A (2013) Assessments of Adherence to Hypertension Medications and Associated Factors among Patients Attending Tikur Anbessa Specialized Hospital Renal Unit, Addis Ababa. International Journal of Nursing Science 3: 1-6

17. Benner JS, Pollack MF, Smith TW, Bullano MF, Willey VJ, et al. (2005) Association between short-term effectiveness of statins and long-term adherence to lipid-lowering therapy. Am J Health Syst Pharm 62: 1468-1475.

18. Nelson MR, Reid CM, Ryan P, Willson K, Yelland L (2006) Self-reported adherence with medication and cardiovascular disease outcomes in the Second Australian National Blood Pressure Study (ANBP2). Med J Aust 185 487-489.

19. Thomas A (2010) Factors affecting compliance with anti-hypertensive drug treatment and required lifestyle modifications among hypertensive patients. University of south Africa 67-198.

20. Roland Nnaemeka (2012) Assessment of patient's antihypertensive medication adherence level in non-comorbid hypertension in a tertiary hospital in Nigeria. Int J Pharm Biomed Sci 3: 47-54.

21. Azlin B, Hatta S, Norzila Z, Sharifa Ezat WP (2007) Health locus of control among non- compliance hypertensive patients undergoing pharmacotherapy. Malaysian Journal of Psychiatry 16: 20-39.

22. Ahmed N, Abdul Khaliq M, Shah SH, Anwar W (2008) Compliance to antihypertensive drugs, salt restriction, exercise and control of systemic hypertension in hypertensive patients at Abbottabad. J Ayub Med Coll Abbottabad 20: 66-69.

23. Becker M (1974) The Health Belief Model and personal health behaviour Health Educ Monogr 2: 376-423.

24. Benson J, Britten N (2003) Patients' views about taking antihypertensive drugs: questionnaire study. BMJ 326: 1314-1315. 